\title{
Abnormalities of horizontal gaze. Clinical, oculographic and magnetic resonance imaging findings. II Gaze palsy and internuclear ophthalmoplegia
}

\author{
A M Bronstein, P Rudge, M A Gresty, G Du Boulay, Joan Morris
}

\begin{abstract}
The site of lesions responsible for horizontal gaze palsy and various types of internuclear ophthalmoplegia (INO) was established by identifying the common areas where the abnormal MRI signals from patients with a given ocular-motor disorder overlapped. Patients with unilateral gaze palsy had lesions in the paramedian area of the pons, including the abducens nucleus, the lateral part of the nucleus reticularis pontis caudalis and the nucleus reticularis pontis oralis. Patients with abducens nucleus lesions showed additional clinical signs of lateral rectus weakness. Lesions responsible for bilateral gaze palsy involved the pontine tegmental raphe. Since this region contains the saccadic omnipause neurons, this finding suggests that damage to omnipause cells produces slowing of saccades rather than opsoclonus, as previously proposed. All INOs, regardless of the presence of impaired abduction or convergence, had similar MRI appearances. Frequently the lesions in patients with INO, were not confined to the medial longitudinal fasciculus (MLF) but also involved neighbouring structures at the pontine and mid-brain levels. There was a statistically significant association between the clinical severity of the INO and the presence of abnormal abduction or convergence. The findings suggest that the lesions outside the MLF, which may affect abducens, gaze or convergence pathways, are responsible for the presence of features additional to INO, depending on the magnitude of functional disruption they produce.
\end{abstract}

The difficulty in identifying the site of lesions responsible for specific ocular-motor defects has been a major obstacle to a better clinical understanding of many neuro-ophthalmological syndromes. In the preceding paper ${ }^{1}$ we presented magnetic resonance imaging (MRI) and electro-oculographic data from a group of patients with lateral rectus weakness of central origin showing that, if the images from the scans are overlapped and processed statistically, it is possible to obtain good clinical/ topographic correlations. It was found that the preferred site of lesions was the posterior half of the intra-brainstem abducens fasciculus, which agrees with the present view that lesions of the abducens nucleus itself produce conjugate gaze palsy rather than isolated lateral rectus weakness. ${ }^{2-4}$ In this paper we present the findings in patients with horizontal gaze palsy and with internuclear ophthalmoplegia (INO).

An outstanding problem in human gaze palsies has been to locate in vivo the paramedian pontine reticular formation (PPRF), which is the immediate pre-motor centre for saccade generation. Although initially defined by animal workers in functional terms as the area of the pontine tegmentum whose damage leads to a gaze palsy, recent single unit recording studies have shown that the PPRF is a conglomerate of various groups of cells with different functions and properties. ${ }^{5}$ Accordingly, the possibility arises that selective lesions within the PPRF might affect horizontal gaze in different ways. In this paper we will present some evidence supporting this view.

With respect to INO, one of our interests was to determine the cause of slow abduction found in some patients. Conceivably, the slow abduction might be due to an extension of the lesion outside the medial longitudinal fasciculus (MLF) into either the PPRF or the abducens nucleus or fasciculus. ${ }^{6}$ Alternatively it has been postulated that disordered inhibition of the antagonist medial rectus, also produced by the MLF lesion, slows the abducting movement. ${ }^{7}$ This view, however, assumed that the lesions were confined to the MLF. We have reexamined this question by using the MRI to define the size and/or location of lesions in these two types of INO.

\section{Material and methods}

The methodology has been fully described in the companion paper ${ }^{1}$ so that a brief comment will suffice here. The identification of patients with INO and horizontal gaze palsy was made on a clinical basis. Separate eyes DC electrooculography was used to confirm the presence of INO and to distinguish between INOs with normal and slowed abduction, according to the lower limit of abducting velocity (mean-2SD) in our normal population. ${ }^{6}$ More information on the patients will be found in the results section of each group.

Three separate analyses of the MRI scans were made; (1) identification of the brainstem area where the areas of abnormal MRI signal 
Figure 1 MRI scans, SE sequences, of a patient with

Syndrome" due to a brain stem vascular event, possibly a haemorrhage, at a low (left) and upper (right) pontine level. In this and subsequent figures, the left side of the scan the patient. The arrows point to the abnormal MRI signal. $a$ "One and $a$ Half corresponds to right side of
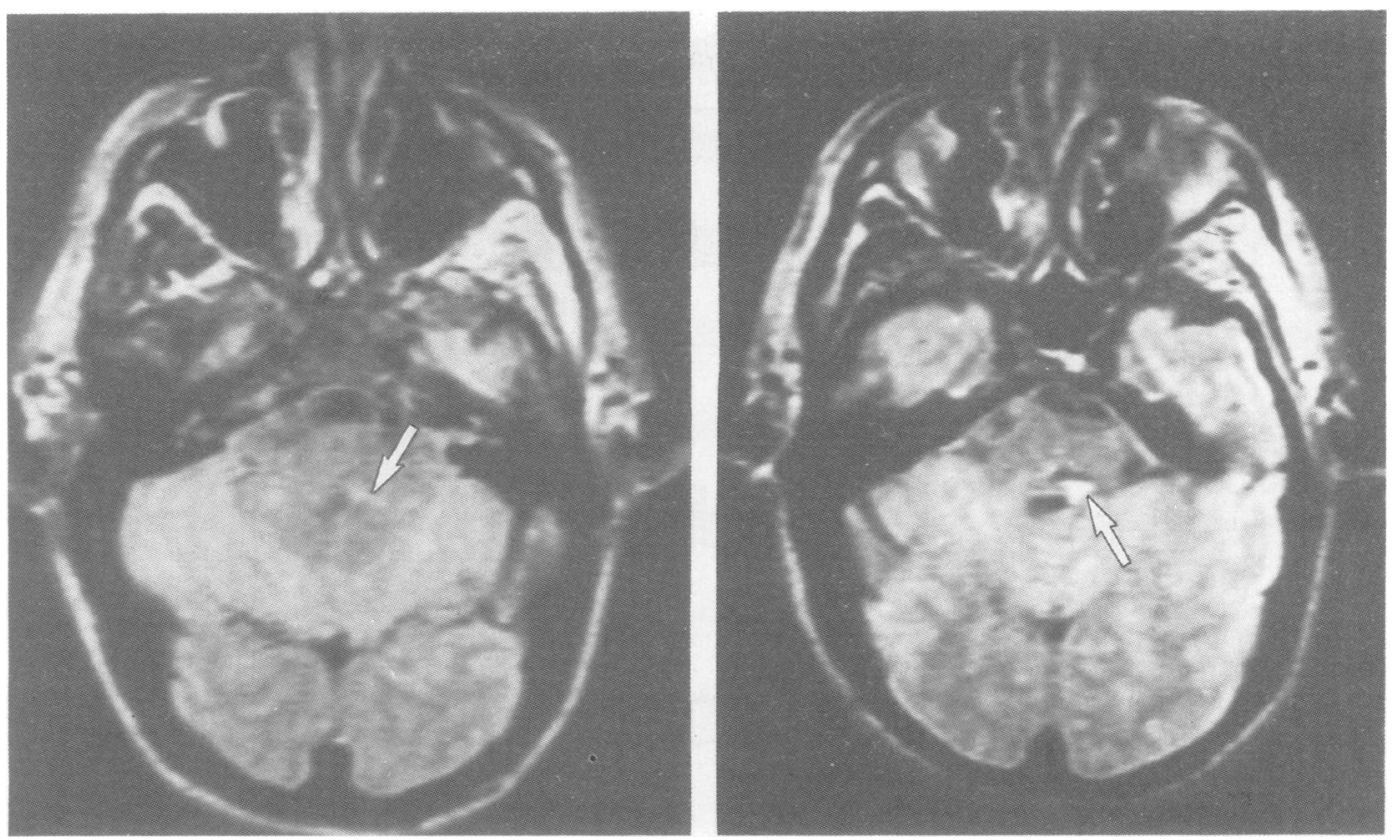

overlap in at least $50 \%$ of the patients in the same group $\left(\mathrm{OL}_{50}\right) ;(2)$ statistical analysis to identify which areas of a brainstem matrix have overlapping areas of abnormal MRI signal which could not have occurred by chance $(\mathrm{p}<$ 0.05 ) and (3) blind assessment of each individual scan (enlarged and traced onto acetate sheets) to identify the probable structures involved by the areas of abnormal MRI signal.

The nomenclature adopted for the reticular nuclei was that proposed by Olszewski and Baxter. $^{8}$

\section{Results:}

I. Unilateral gaze palsy:

Seven patients were studied, five of whom had MS or a single brainstem episode that was probably demyelinating, one had a vascular episode and one a pontine glioma. The gaze palsy was mild in five cases, that is, unilateral conjugate slowness of saccades, and severe in two. Four of these patients had an INO on the same side ("one and a half" syndrome). Three had evidence for an additional mild VI palsy to the side of the gaze palsy. None of the cases had abnormalities of vertical saccades or gaze limitations in that plane.

Six patients had abnormal signals at the low pons level; an example is shown (fig 1, left). There was good agreement between the $\mathrm{OL}_{50}$ area (fig 2) and the squares in the brainstem

Figure $2 O L_{50}$ (hatched) area at the level of the low pontine cut in the group of patients with unilateral gaze palsy. Anatomical structures as in fig $2(b)$ in the companion paper.' matrix with statistically significant overlap (fig 3 ). The region involved is clearly distinct from that shown in the companion paper for lateral rectus weakness; it is larger and more dorsolaterally placed, affecting the abducens nucleus and the lateral part of the nucleus reticularis pontis (NRP) caudalis. Examination of the individual acetates showed that the areas of abnormal signal were located in the VI nucleus in one case, in the lateral portion of the NRP caudalis in one case or both structures in four cases (table 1). In the three cases with additional VI palsies, two cases had abnormal signal in the area of the VI nucleus and the other had abnormal signals in both the VI nucleus and fasciculus.

All patients had abnormal signals in higher pontine sections (for example, fig 1, right). The NRP oralis was consistently affected as shown by the analysis of individual patients (table 1), the $\mathrm{OL}_{50}$ (fig 4) and the statistical procedure (fig 3).

The area containing the MLF showed abnormal signal ipsilaterally in all cases; in spite of this, three out of seven patients did not have evidence of INO. In the patients who did, (that is, those with "one and a half" syndrome) two had abnormal signal on the MLF at a pontine level and two in the midbrain. The $\mathrm{OL}_{50}$ (fig 4) and the statistically significant square from the brainstem matrix (fig 3 ) bounded on the MLF in the upper pontine cut but were clear of the fasciculi at the lower pons level (figs 2 and 3).

\section{Bilateral gaze palsy}

Seven patients with mild and two with severe bilateral gaze palsy were studied. Of these, seven had MS or a single brainstem episode that was probably demyelinating, and two had vascular disease.

Seven patients had abnormal MRI signal in the lower pontine cut, though in one (case 3, table 2) it was very lateral and would not involve any ocular-motor structure. Five patients had abnormal MRIs of the upper pons.

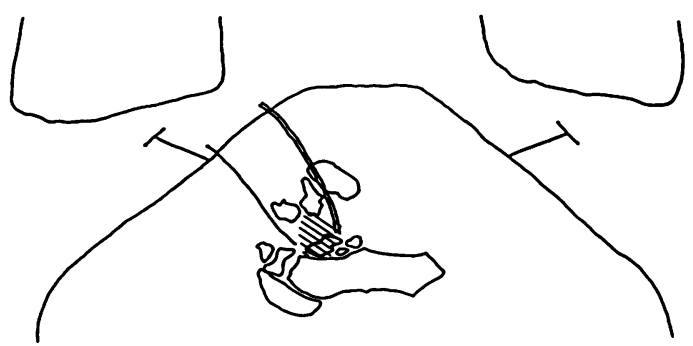


Gaze palsy
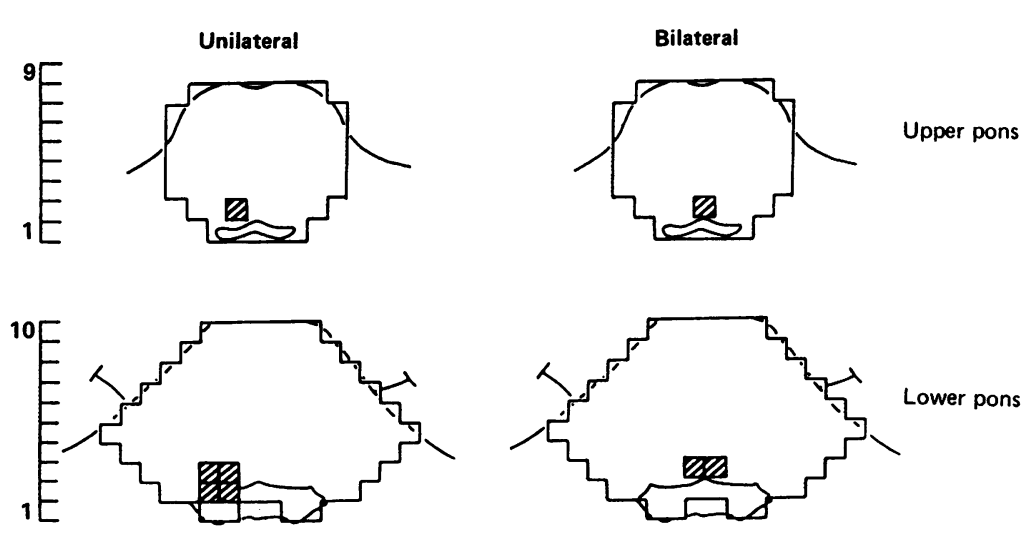

INO
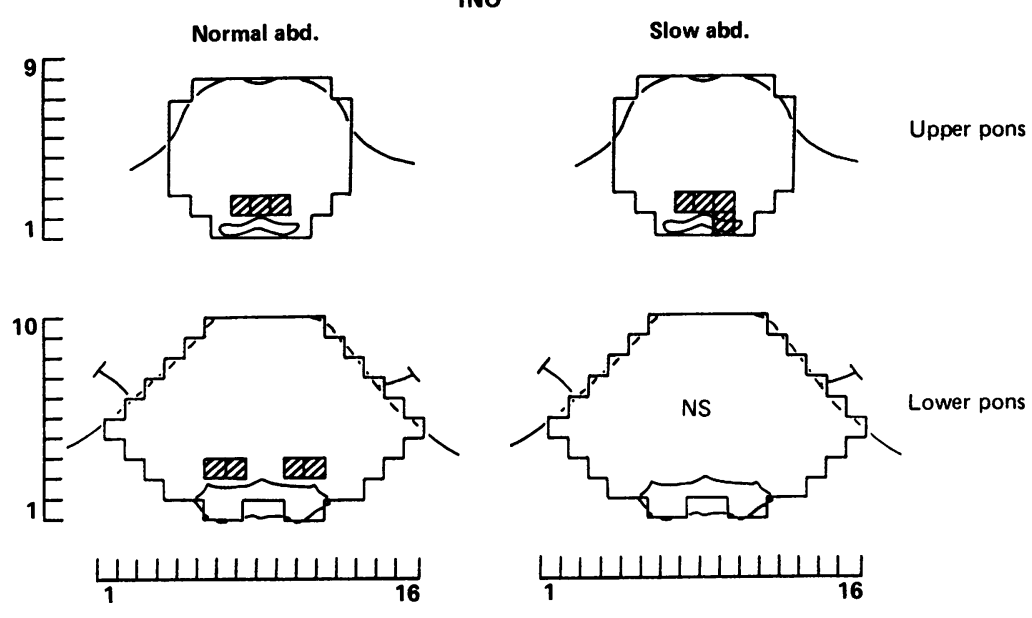

Figure 3 Grid squares at the low and high pontine levels where significant $(p<0.05)$ overlaps of abnormal signals occurred in patients with gaze palsy and INO. Note the similarity between $O L_{50}$ areas in figs $2,4,6,8$. There was no significant overlap at the low pons cut for INO with slow abduction because the $O L_{50}$ area present in this group was much smaller than the resolution of the grid squares (fig 8 , lower right).

Although some scans from individual patients showed abnormal signals involving abducens and reticular nuclei (Tables 2 and 3 ), the smaller MRI abnormal signals (for example, fig

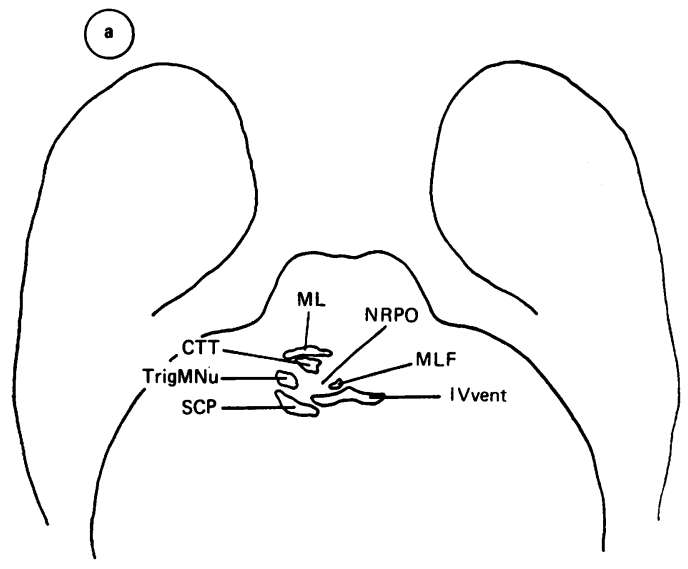

(b)

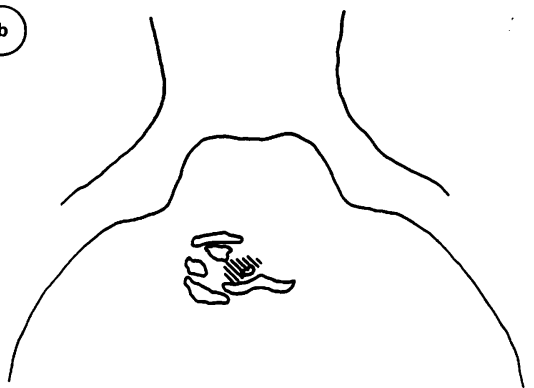

Figure 4 a: Significant structures present at the level of the upper pons. NRPO: nucleus reticularis pontis oralis.

TrigMNu: trigeminal motor nucleus. Other abbreviations as in fig $2(b)$ in the companion paper. $b: O L_{50} s$ (hatched) at the level of the upper pontine cuts of patients with unilateral gaze palsy.

5) and $\mathrm{OL}_{50}$ areas (fig 6) were restricted to the midline structures of the pons, namely, the raphe and MLFs. This was confirmed in the statistical analysis illustrated in fig 3 . There was no evidence from the MRI that any of the patients had extensive bilateral involvement of the reticular or abducens nuclei.

Five of the nine cases with bilateral horizontal gaze palsy had either slowness of vertical saccades or some limitation of up gaze. MRI revealed no lesions in one of these patients. One had abnormal signals placed so laterally that they were unlikely to involve any oculomotor

Table 1 Distribution of abnormal MRI signal in the pons, in patients with unilateral gaze palsy

\begin{tabular}{|c|c|c|c|c|c|c|c|c|c|}
\hline \multirow[b]{2}{*}{ Patient } & \multirow{2}{*}{$\begin{array}{l}\text { "One and } \\
\text { a Half" }\end{array}$} & \multirow{2}{*}{$\begin{array}{l}\text { Additional } \\
\text { VI Palsy }\end{array}$} & \multicolumn{5}{|c|}{ LOW PONS } & \multicolumn{2}{|c|}{ HIGH PONS } \\
\hline & & & $V I N u$ & VI Fasc & NRPC Lat & NRPC med & $M L F$ & NRPO & $M L F$ \\
\hline $\begin{array}{l}1 \\
2 \\
3 \\
4 \\
5 \\
6 \\
7\end{array}$ & $\begin{array}{l}+ \\
+ \\
+ \\
+ \\
- \\
- \\
-\end{array}$ & $\begin{array}{l}+ \\
- \\
- \\
+ \\
- \\
- \\
+\end{array}$ & $\begin{array}{l}++++ \\
- \\
++++ \\
+++ \\
- \\
++++ \\
+++\end{array}$ & $\begin{array}{l}++++ \\
- \\
++++ \\
- \\
+ \\
\pm\end{array}$ & $\begin{array}{l}++++ \\
+++ \\
++++ \\
\pm \\
- \\
++++ \\
+\end{array}$ & $\begin{array}{l}++++ \\
- \\
++++ \\
- \\
++++ \\
-\end{array}$ & $\begin{array}{l}++++ \\
- \\
+++ \\
- \\
+++ \\
-\end{array}$ & $\begin{array}{l}++++ \\
+ \\
++ \\
++++ \\
+++ \\
+ \\
++++\end{array}$ & $\begin{array}{l}++++ \\
- \\
+++ \\
+ \\
+++ \\
+++ \\
+++\end{array}$ \\
\hline
\end{tabular}

In tables I to III the + signs under a particular structure estimate their degree of intersection with an area of abnormal MRI signal $\left(++++=100^{\circ}\right.$; see the end of the material and methods section in the companion paper for a more detailed explanation).

Table 2 Distribution of abnormal MRI signal at the low pontine level in patients with bilateral gaze palsy

\begin{tabular}{|c|c|c|c|c|c|c|c|c|c|c|c|}
\hline \multirow[b]{2}{*}{ Patient } & \multicolumn{2}{|c|}{ Clinical VI } & \multicolumn{2}{|c|}{ VI Nucleus } & \multicolumn{2}{|c|}{ VI Fasciculus } & \multicolumn{2}{|l|}{$N R P C$} & \multicolumn{2}{|l|}{$M L F$} & \multirow[b]{2}{*}{ Raphe } \\
\hline & $R$ & $L$ & $R$ & $L$ & $R$ & $L$ & $R$ & $L$ & $R$ & $L$ & \\
\hline $\begin{array}{l}1 \\
2 \\
3 \\
4 \\
5 \\
6 \\
7 \\
8 \\
9\end{array}$ & $\begin{array}{l}+ \\
+ \\
+ \\
+ \\
+ \\
+ \\
+ \\
+\end{array}$ & $\begin{array}{l}+ \\
+ \\
+ \\
+ \\
+ \\
- \\
-\end{array}$ & $\begin{array}{l} \pm \\
+ \\
- \\
- \\
- \\
+ \\
- \\
\text { no } \\
\text { no }\end{array}$ & $\begin{array}{l} \pm \\
\pm \\
- \\
++++ \\
- \\
\pm \\
\pm \\
\text { on in this cut } \\
\text { on in any cut }\end{array}$ & $\begin{array}{l}\overline{+}+++ \\
\overline{-} \\
\overline{-} \\
\overline{-}\end{array}$ & $\begin{array}{l}\overline{ \pm} \\
\overline{+} \\
\pm \\
- \\
-\end{array}$ & $\begin{array}{l}\overline{+}++ \\
\overline{-} \\
\bar{z} \\
\overline{ \pm}\end{array}$ & $\begin{array}{l}\overline{-} \\
\overline{+} \\
+ \\
- \\
-\end{array}$ & $\begin{array}{l}++++ \\
+++ \\
- \\
- \\
++ \\
+++ \\
++++\end{array}$ & $\begin{array}{l}++++ \\
- \\
- \\
++ \\
++ \\
+++ \\
-\end{array}$ & $\begin{array}{l}++++ \\
- \\
- \\
++++ \\
++++ \\
++++\end{array}$ \\
\hline
\end{tabular}


Table 3 Distribution of abnormal MRI signal at the upper pontine level in patients with bilateral gaze palsy

\begin{tabular}{lllllll}
\hline & \multicolumn{2}{l}{$N R P O$} & & & \multicolumn{2}{l}{$M L F$} \\
\cline { 2 - 3 } & Patient & $R$ & $L$ & $R$ & $L$ & Raphe \\
\hline 2 & +++ & - & + & + & + & + \\
4 & ++ & ++++ & +++ & ++++ & +++ \\
5 & - & - & +++ & +++ & ++++ \\
6 & - & - & + & + & + \\
8 & - & - & - & - & ++ \\
\hline
\end{tabular}

structures. Of the remaining three patients all had abnormal signals in the pons and two had additional abnormalities in the midbrain.

\section{Internuclear ophthalmoplegia}

Twenty eight patients with INOs were studied (table 4). Fourteen patients had definite MS; 13 of these had bilateral INO and one had a unilateral INO. The other 14 patients had INOs associated with relatively acute disorders without definite diagnosis; 10 of these had an acute brainstem episode which was probably demyelinating. The INOs were unilateral in four cases and bilateral, although frequently asymmetrical, in 10 .

The INOs were subgrouped according to whether abduction was normal or slow. Abduction was slowed in 11 cases, all of whom had bilateral INO, and was normal in 17. The general distribution of the abnormal signals is presented in table 4 and examples of scans are shown in fig 7 .

Only in the high pontine cut did the abnormal signals overlap significantly on both MLFs, without apparent differences between the two groups (see fig 8 for $\mathrm{OL}_{50}$ and fig 3 for statistical results). In the low pontine cut, the $\mathrm{OL}_{50}$ in both groups did not appear to involve the MLFs. In the slow abduction group there was a very small unilateral $\mathrm{OL}_{50}$ area placed between the MLF and the origin of the abducens fasciculus (fig 8), which was not statistically significant (fig 3 ). In the group with normal abduction the $\mathrm{OL}_{50}$ and statis- tically significant overlaps occurred outside (ventrolateral) to the MLFs, in the area of the lateral NRP caudalis.

In terms of severity INOs can be divided into amplitude INOs, in which there is a limitation to the excursion of the adducting eye, and velocity INOs, in which adducting saccades are slow but with no restriction in amplitude. There was a strong association between the presence of slowed abduction and the more severe (amplitude) INO (chi square < 6.76; $\mathrm{p}<0.01$; see table 4 , adduction and abduction columns). In a clinically homogeneous group (patients with definite MS and bilateral INO), the area occupied by the abnormal signals in the pons (low and upper pons cuts measured together in $\mathrm{mm}^{2}$ from the acetates), was significantly larger in the group with slowed abduction than in those with normal abduction (Slow abduction: 347 SD134 $\mathrm{mm}^{2}, \quad \mathrm{n}=4$ patients; Normal abduction: $140 \mathrm{SD} 92 \mathrm{~mm}^{2}$, $\mathrm{n}=8$ patients; Mann-Whitney test, $\mathrm{Z}=$ $2 \cdot 377, \mathrm{p}=0.017$ ).

INOs were also divided into two groups, according to whether they had normal or abnormal/absent convergence. No systematic differences were detected between the MRIs in these two groups, although the degree of certainty of identifying abnormal signal in the periaqueductal area was low due to the presence of normal high signal in that area $-^{\star}$. The frequency of abnormal signals in the mid brain was similar in the two groups (chi square

*FOOTNOTE: Interpretation of SE scans of the midbrain presents a difficulty not experienced elsewhere in our material It is common to find a band of higher signal surrounding the aqueduct in both patients and subjects with no evidence of brainstem disease. The finding parallels that in the cerebrum where a narrow smooth band of high signal is often seen around the tip of the frontal and occipital horns. A similar band is also commonly visible around the fourth ventricle. In both these situations the distinction between the narrowness and evenness of the band and any adjacent lesions tends to be obvious. Around the aqueduct the (possibly normal) high to be obvious. Around the aqueduct the (possibly normal) high signal band is usually very narrow. If it was wide, or, especially if it was irregular we have suspected the presence of pathological change. Small focal been accepted as confirmation of disease.
Figure 5 SE MRI scans at low (left) and high (right) pontine cut of two patients with a bilateral horizontal gaze palsy due to an acute brain stem episode, probably demyelinating. The thick arrow points to the central artefact found in earlier scans.
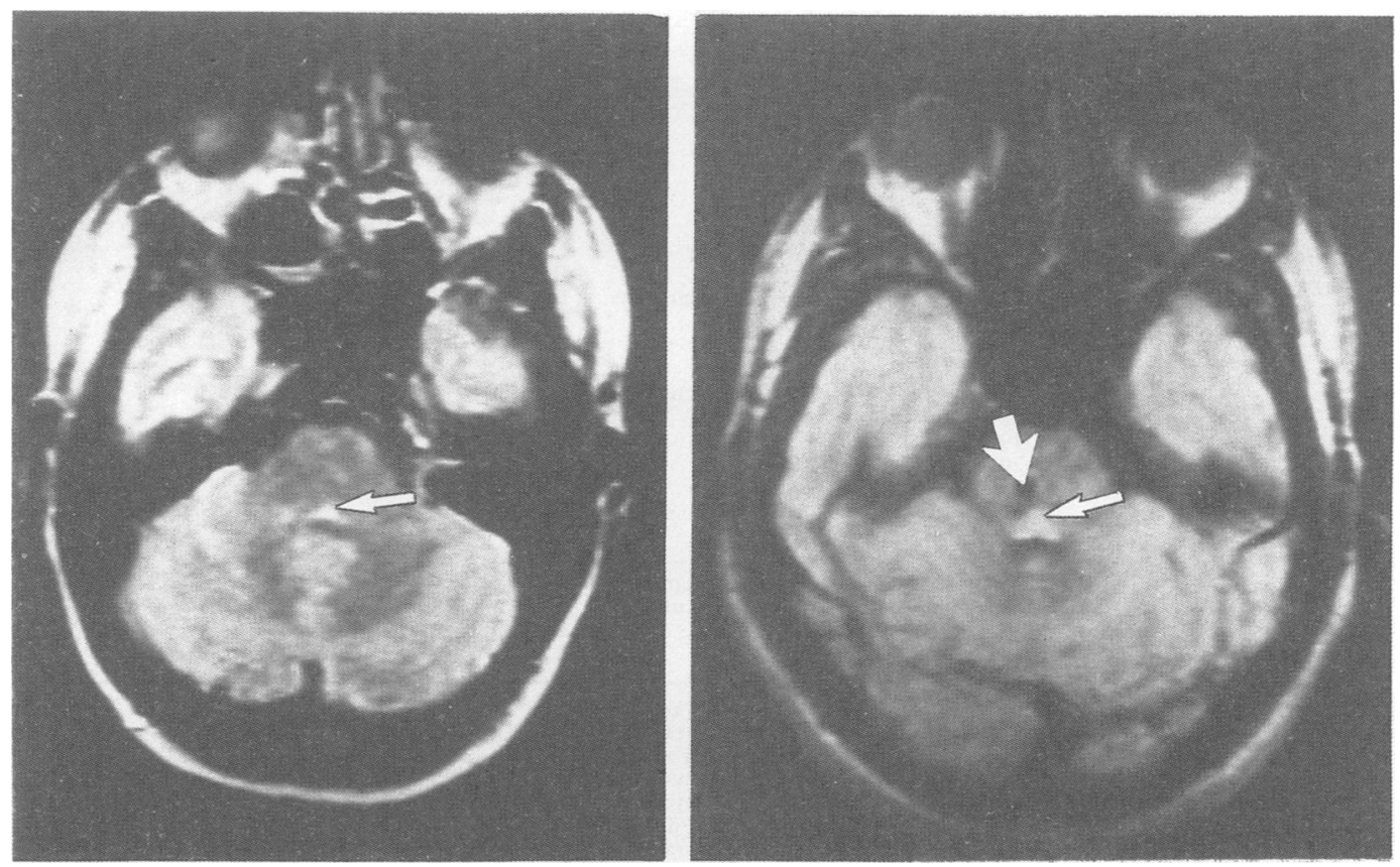
Figure $6 \quad O L_{50}$ (hatched) areas at the levels of the

low (a) and high (b)

pontine cuts in patients with bilateral gaze palsy.
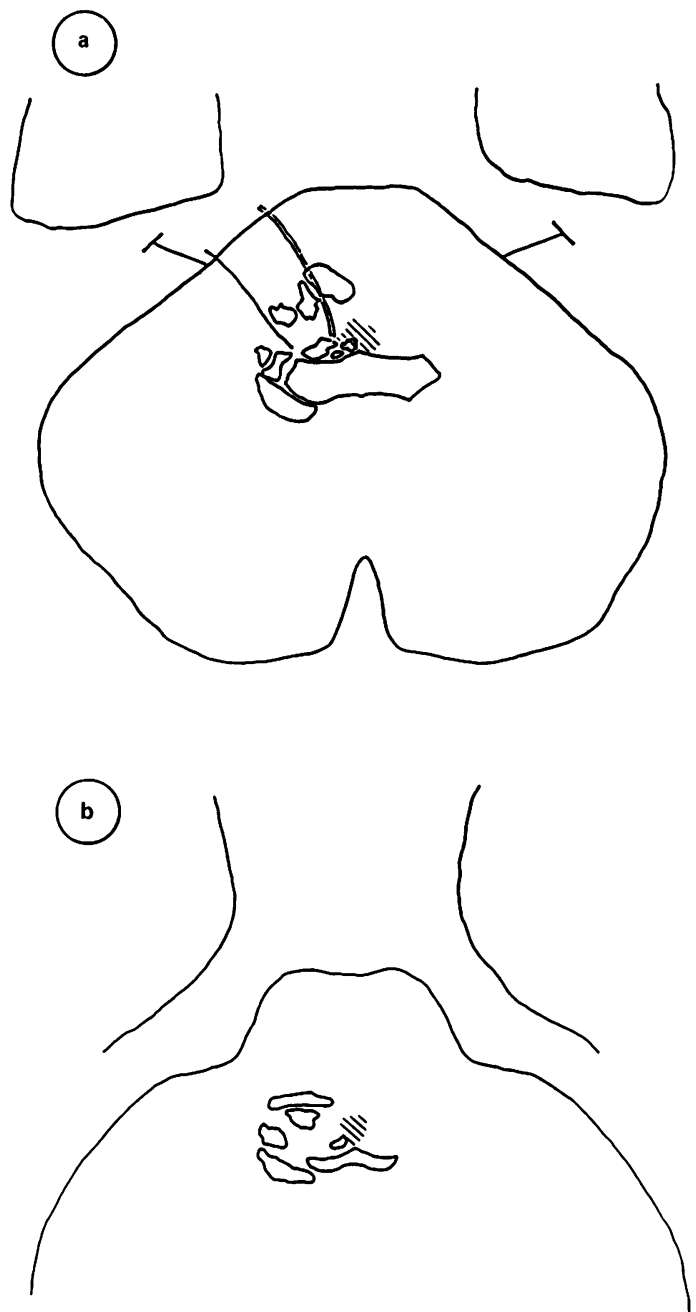

$=1.80 ; \mathrm{p}>0.05)$. There was a significant association between amplitude INOs, which tended to have abnormal convergence (seven out of 12) and velocity INOs, in which convergence was usually normal (15 out of 18) (chi square $=3.90 ; \mathrm{p}<0.05 ;$ table 4 )

\section{Discussion}

I Unilateral gaze palsy

Recent reports have established that a unilateral gaze palsy can be produced either by a PPRF or a VI nucleus lesion. ${ }^{3410}$ Our data relate to two aspects of gaze palsies. The first is the development of a technique which is adequate for imaging the area containing the PPRF. The second concerns the clinical problem of differentiating between VI nucleus and PPRF lesions; there are reports that severe supranuclear palsies can be distinguished from VI nucleus lesions by the "doll's head" manoeuvre (vestibular ocular reflex) because the vestibular fibres to the VI nucleus run separately from those responsible for lateral saccades. ${ }^{11}$ Consequently, in a lesion of the PPRF, "doll's head" eye movements in the direction of the palsy will be intact whereas in a nuclear lesion all eye movements are lost. ${ }^{49}$ However, in a partial gaze paresis this differentiation cannot easily be made.

Most of our patients with a unilateral gaze palsy had involvement of the region containing the NRP caudalis and oralis. This coincides with the structures, indentified in animals as responsible for lateral gaze, which are known to contain the PPRF burst neurons. ${ }^{12-14}$ Thus, the

Table 4 Main clinical, ocular-motor and MRI findings in patients with INO

\begin{tabular}{|c|c|c|c|c|c|c|c|c|c|c|}
\hline \multirow[b]{2}{*}{ Patient } & \multirow[b]{2}{*}{ Age } & \multirow[b]{2}{*}{ Sex } & \multirow[b]{2}{*}{ Diagnosis } & \multirow[b]{2}{*}{ Side $^{t}$} & \multirow[b]{2}{*}{ Adduction $^{2}$} & \multirow[b]{2}{*}{ Abduction $^{3}$} & \multirow[b]{2}{*}{ Convergence ${ }^{4}$} & \multicolumn{3}{|c|}{ MRI lesions' } \\
\hline & & & & & & & & $\begin{array}{l}\text { Lower } \\
\text { pons }\end{array}$ & $\begin{array}{l}\text { Upper } \\
\text { pons }\end{array}$ & $\begin{array}{l}\text { Mid } \\
\text { brain }\end{array}$ \\
\hline $\begin{array}{r}1 \\
2 \\
3 \\
4 \\
5 \\
6 \\
7 \\
8 \\
9 \\
10 \\
11 \\
12 \\
13 \\
14 \\
15 \\
16 \\
17 \\
18 \\
19 \\
20 \\
21 \\
22 \\
23 \\
24 \\
25 \\
26 \\
27 \\
28\end{array}$ & $\begin{array}{l}29 \\
31 \\
58 \\
35 \\
23 \\
40 \\
38 \\
29 \\
34 \\
29 \\
20 \\
27 \\
65 \\
23 \\
37 \\
31 \\
48 \\
30 \\
44 \\
40 \\
42 \\
66 \\
30 \\
52 \\
42 \\
21 \\
40 \\
24\end{array}$ & $\begin{array}{l}F \\
M \\
F \\
F \\
F \\
F \\
F \\
M \\
F \\
M \\
F \\
F \\
M \\
M \\
M \\
F \\
M \\
F \\
F \\
M \\
F \\
M \\
M \\
F \\
M \\
F \\
M \\
M\end{array}$ & $\begin{array}{l}\text { MS } \\
\text { MS } \\
\text { MS } \\
\text { MS } \\
\text { MS } \\
\text { MS } \\
\text { MS } \\
\text { MS } \\
\text { MS } \\
\text { MS } \\
\text { Bst } \\
\text { Bst } \\
\text { Vascular? } \\
\text { Bst } \\
\text { Bst } \\
\text { Bst } \\
\text { Vascular? } \\
\text { MS } \\
\text { MS } \\
\text { MS } \\
\text { MS } \\
\text { Traumatic? } \\
\text { Bst } \\
\text { Bst } \\
\text { Traumatic? } \\
\text { Vascular? } \\
\text { Bst } \\
\text { Bst }\end{array}$ & $\begin{array}{l}\text { U } \\
\mathbf{B} \\
\mathbf{B} \\
\mathbf{B} \\
\mathbf{B} \\
\mathbf{B} \\
\mathbf{B} \\
\mathbf{B} \\
\mathbf{B} \\
\mathbf{B} \\
\mathbf{U} \\
\mathbf{B} \\
\mathbf{B} \\
\mathbf{U} \\
\mathbf{U} \\
\mathbf{B} \\
\mathbf{U} \\
\mathbf{B} \\
\mathbf{B} \\
\mathbf{B} \\
\mathbf{B} \\
\mathbf{B} \\
\mathbf{B} \\
\mathbf{B} \\
\mathbf{B} \\
\mathbf{B} \\
\mathbf{B} \\
\mathbf{B}\end{array}$ & $\begin{array}{l}\text { V } \\
\text { A.V } \\
\text { V } \\
\text { V } \\
\text { V } \\
\text { V } \\
\text { V } \\
\text { V } \\
\text { V } \\
\text { V } \\
\text { V } \\
\text { V } \\
\text { V } \\
\text { V } \\
\text { V } \\
\text { A } \\
\text { A } \\
\text { A } \\
\text { A } \\
\text { A.V. } \\
\text { A } \\
\text { A } \\
\text { A } \\
\text { A } \\
\text { V } \\
\text { A } \\
\text { A } \\
\text { V }\end{array}$ & $\begin{array}{l}\mathbf{N} \\
\mathbf{N} \\
\mathbf{N} \\
\mathbf{N} \\
\mathbf{N} \\
\mathbf{N} \\
\mathbf{N} \\
\mathbf{N} \\
\mathbf{N} \\
\mathbf{N} \\
\mathbf{N} \\
\mathbf{N} \\
\mathbf{N} \\
\mathbf{N} \\
\mathbf{N} \\
\mathbf{N} \\
\mathbf{N} \\
\text { Slow } \\
\text { Slow } \\
\text { Slow } \\
\text { Slow } \\
\text { Slow } \\
\text { Slow } \\
\text { Slow } \\
\text { Slow } \\
\text { Slow } \\
\text { Slow } \\
\text { Slow }\end{array}$ & $\begin{array}{l}\mathbf{N} \\
\mathbf{N} \\
\mathbf{N} \\
\mathbf{N} \\
\mathbf{N} \\
\mathbf{N} \\
\mathbf{N} \\
\mathbf{N} \\
- \\
\mathbf{N} \\
\mathbf{N} \\
\mathbf{N} \\
- \\
\mathbf{N} \\
\mathbf{N} \\
- \\
- \\
\mathbf{N} \\
- \\
- \\
\mathbf{N} \\
\mathbf{N} \\
-\mathbf{N} \\
- \\
\mathbf{N} \\
\mathbf{N}\end{array}$ & $\begin{array}{l}+ \\
+ \\
+ \\
+ \\
+ \\
+ \\
+ \\
+ \\
+ \\
+ \\
+ \\
+ \\
+ \\
+ \\
+ \\
+ \\
+ \\
+ \\
+ \\
+ \\
+ \\
+ \\
+ \\
+ \\
- \\
+ \\
+ \\
+\end{array}$ & $\begin{array}{l}+ \\
+ \\
+ \\
+ \\
- \\
+ \\
- \\
+ \\
+ \\
+ \\
+ \\
- \\
+ \\
+ \\
+ \\
+ \\
+ \\
+ \\
+ \\
+ \\
+ \\
+ \\
+ \\
+ \\
- \\
+ \\
- \\
-\end{array}$ & $\begin{array}{l}+ \\
+ \\
+ \\
- \\
+ \\
- \\
+ \\
+ \\
+ \\
+ \\
+ \\
+ \\
+ \\
- \\
- \\
+ \\
- \\
- \\
+ \\
+ \\
- \\
+ \\
- \\
- \\
- \\
- \\
- \\
-\end{array}$ \\
\hline
\end{tabular}


Figure 7 SE MRI scans at a high pontine cut in two patients with bilateral INO. The one on the left belongs to a patient with normal abduction velocities and the one on the the right to a patient with slow abduction. The low pontine cut appearances (not shown) were normal in the two cases.
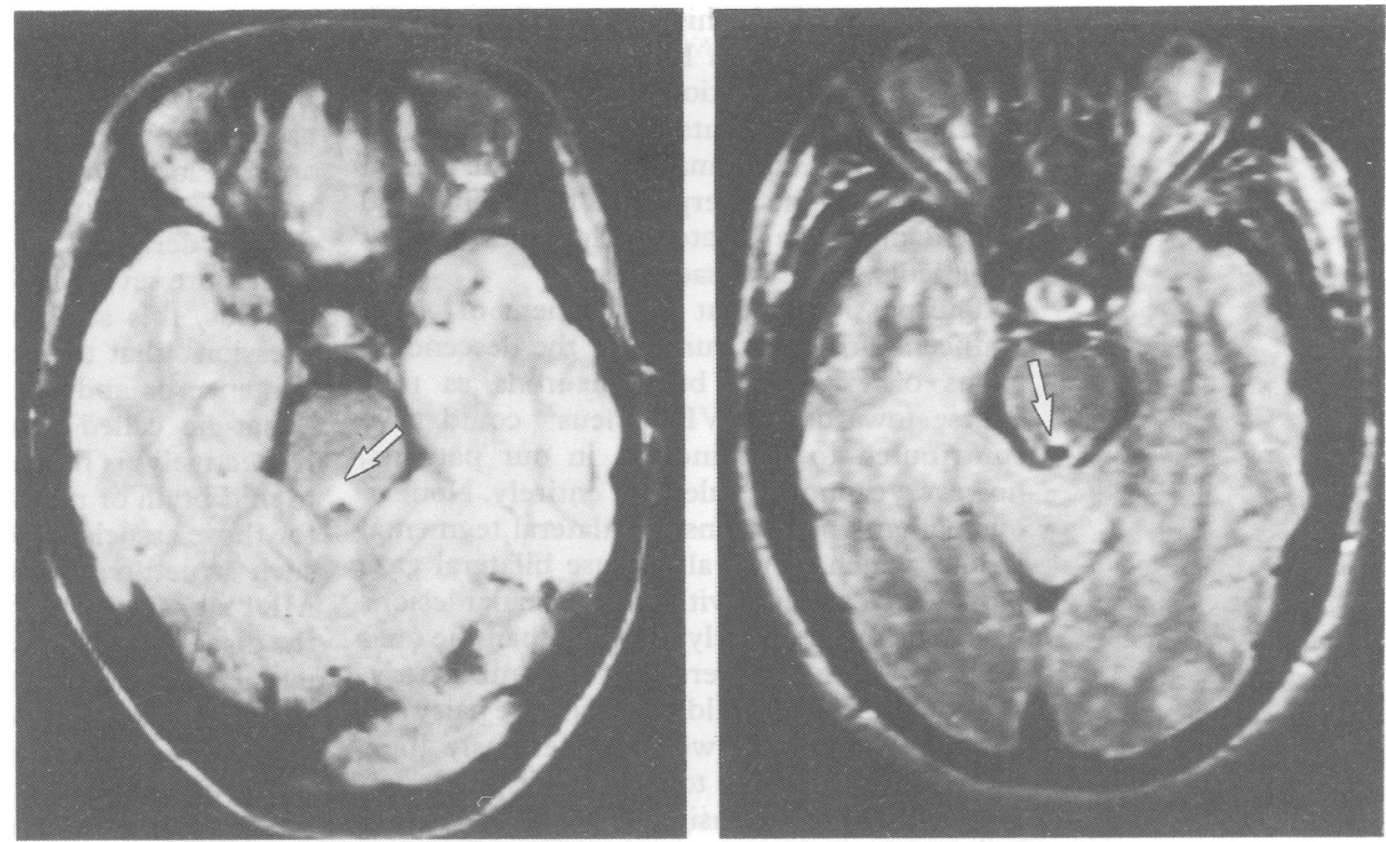

significance of our findings is that the $\mathrm{OL}_{50}$ area drawn for our patients with unilateral gaze palsy is a template which identifies the location of the PPRF on an MR image of the pons. Also, of clinical relevance, the patients with gaze palsy with VI nucleus involvement had signs of additional lateral rectus weakness. Thus, the presence of this sign may be useful in identifying the site of the lesion in the mild gaze palsies which are more typical of demyelinating disease.

Four of the cases with unilateral gaze palsy had an ipsilateral INO, the so called "one and a half' syndrome. Since ipsilateral abnormal signal in the area of the MLF was seen in all patients, regardless of whether they had an INO, it appears that high signal areas in the MRI do not always show a good clinical correlation. The MLF abnormalities sometimes occurred at different levels from those producing the gaze palsy whereas in most previous descriptions of "one and a half" in
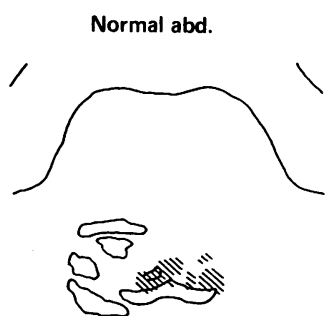

Upper pons

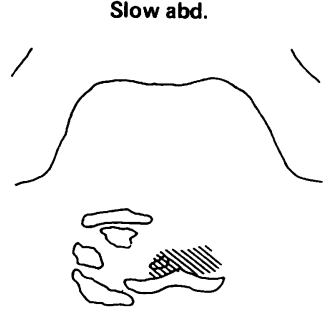

Figure $8 O L_{50}$ ( hatched) in patients with INO, with normal and slow abduction, at the levels of the low and high pontine cuts. vascular and neoplastic disease, it is probable that a single lesion was responsible for the gaze palsy and the INO. ${ }^{915}$

\section{Bilateral gaze palsy}

An unexpected finding in our patients with bilateral gaze palsy was the small areas of abnormal signal confined to midline structures of the pons, probably involving both MLFs and the raphe area ventral to them. The structures involved probably included the nuclei centralis superioris and the medial part of the NRP caudalis. The latter has been recently found to constitute a special subdivision of NRP caudalis, the nucleus raphe interpositus, which contains a specialised type of neuron, the "omnipause cells". ${ }^{1617}$ There were no significant lesions in the area of the abducens nucleus, the NRP oralis or the lateral part of the NRP caudalis.

Omnipause neurons normally inhibit excitatory burst neurons, discharging tonically in between saccades and stopping abruptly during saccades. ${ }^{1318}$ It was first proposed that omnipause neurons are the gate through which descending inputs, for example from the superior colliculus, trigger saccades. Because of this function it was postulated that opsoclonus, a condition in which saccades are incessantly and chaotically generated, resulted from malfunctioning of the omnipause neurons. ${ }^{19}$ More recently an alternative model of the saccade generator has been put forward in which direct stimulation from long-lead burst neurons can initiate the discharge in excitatory burst neurons, with omnipause neurons retaining a less crucial role of modifying saccade dynamics. $^{20}$ To test this hypothesis, Kaneko and Fuchs ${ }^{21}$ produced discrete experimental lesions with ibotenic acid, an axon sparing reversible neurotoxin, in the omnipause area (nucleus raphe interpositus) in two monkeys. The animals developed slowness of saccades, more in the horizontal than in the vertical plane, but no opsoclonus was noted. Our data 
are consistent with this hypothesis and with other observations in humans. For example, pathological examination of the nucleus raphe interpositus in patients with opsoclonus has failed to reveal abnormalities ${ }^{22}$ and the area of the nucleus raphe interpositus has been found to be damaged in isolated pathological reports of patients with slow saccades. ${ }^{23} 24$

The possibility that involvement of either abducens or burst neurons or the descending axons of excitatory burst neurons as they course towards the VI nucleus ${ }^{25}$ could have contributed to the findings in our patients, however, cannot be ruled out entirely. None of our patients had extensive bilateral tegmental lesions which would also cause bilateral gaze palsy. Such patients with large reticular lesions would be more severely disabled than the ones we report here who were alert and ambulatory. We conclude that a mild bilateral gaze palsy in a patient who is otherwise not seriously ill is more likely to be due to a central raphe lesion rather than to extensive bilateral tegmental lesions.

\section{Internuclear ophthalmoplegia}

In our sample of patients with INO the areas with significant overlap coincided with the site of the MLF in the higher pontine cuts. There was no significant overlap in the region of the MLF in the low cuts. From this evidence it would seem that in demyelinating disease the prevalent lesions producing INO are in the MLF rostral to the VI nucleus above the level at which axons from the abducens neurons decussate and enter the fasciculi.

Although it is accepted that INO is due to lesions of the MLF, ${ }^{26}$ there is doubt about the origin of impaired abduction and convergence which are features frequently accompanying INOs. The MRIs of patients with both pure INOs and INOs with slow abduction showed areas of abnormal signal including the MLF but with considerable extension to adjacent structures including the abducens nucleus and fasciculus, NRP caudalis-oralis and the raphe area, all of which could impair abduction. In our study slow abduction was associated with bilateral, more severe (amplitude) INOs and with more extensive pontine lesions. This would suggest that slow abduction depends on the degree of functional impairment of these adjacent structures. Unfortunately, with the current limitation of MRI technique, the degree of functional impairment of a structure by a lesion cannot be determined from the appearance on the scan.

The presence of slow abduction in INO has been attributed to a single MLF lesion interrupting inhibitory fibres in the MLF which would normally silence the medial rectus motor neuron during abducting saccades. ${ }^{7}$ Evidence for this theory was based on reports showing disinhibited EMG activity in the medial rectus in INO. ${ }^{27}$ However, against this explanation is firstly, that the authors assumed that no other lesions involving horizontal gaze centres were present ${ }^{7}$ which our present work indicates is unlikely, and secondly, repeated experimental studies have failed to find in- hibitory fibres in the MLF. ${ }^{28-30}$

The MRI revealed abnormalities in the midbrain as frequently in patients with normal as in those with abnormal convergence and no specific location was systematically associated with impaired convergence. As with abduction failure, deranged convergence was associated with more severe INOs.

Thus, this study agrees with Cogan's impression $^{31}$ that the presence of abnormal convergence or abduction in patients with INO (what he called anterior or posterior INO, respectively) is related to concomitant damage to mid brain or pontine structures responsible for those associated signs. Our data show that such structures, as indicated by an abnormal MRI signal, are more frequently involved by the disease process than was previously suspected. However, the presence of an abnormal signal does not necessarily indicate impairment. It is the magnitude of the functional disruption produced by the lesion that determines whether a defect will become clinically manifest.

We are grateful to the Multiple Sclerosis Society of Great Britain and Northern Ireland for generous financial support and to Drs I Ormerod, D Miller, A Kermode and Mr D MacManus of the NMR Research Group at the National Hospital, Queen Square for their patient work in the collection of the MR images.

1 Bronstein AM, Morris J, Du Boulay G, Gresty MA, Rudge P. Abnormalities of horizontal gaze. Clinical, oculographic and magnetic resonance imaging findings. I Abducens palsy. J Neurol Neurosurg Psychiatry 1990; 53:194-99.

2 Carpenter MB, McMasters RE, Hanna GR. Disturbances of conjugate horizontal eye movements in the monkey. Arch Neurol 1963;8:231-47.

3 Meienberg O, Buttner-Ennever JA, Kraus-Ruppert R. Lesion of the abducens nucleus as the cause of a conjugate gaze paralysis. G Lennerstrand, DS Zee, EL Keller, eds. Functional Basis of Ocular Motility Disorders. Oxford: Pergamon Press, 1982:527-9.

4 Pierrot-Deseilligny $\mathrm{Ch}$, Goasguen J. Isolated abducens nucleus damage due to histocytosis X. Brain 1984; 107:1019-32.

5 Fuchs AF, Kaneko CRS, Scudder CA. Brainstem control of saccadic eye movements. Ann Rev Neurosci 1985;8: 307-37.

6 Bird AC, Leech J. Internuclear ophthalmoplegia. $\mathrm{Br} J$ Ophthal 1976;60:645-51.

7 Feldon SE, Hoyt WF, Stark L. Disordered inhibition in internuclear ophthalmoplegia. Brain 1980;103:113-7.

8 Olszewski J, Baxter D. Cytoarchitecture of the human brain stem. Basel: Reinhardt 1954

9 Pierrot-Deseilligny CH, Chain F, Serdaru M, Gray F, L'Hermitte F. The "One-and-a-half" Syndrome. Electro-oculographic analyses of five cases with deductions about the physiological mechanisms of lateral gaze. Brain 1981;104:665-99.

10 Kommerell G, Henn V, Bach M, Lucking CH. Unilateral lesion of the paramedian pontine reticular formation. Neuro-ophthal 1987;7:93-8.

11 Henn V, Lang W, Hepp K, Reisine H. Experimental gaze palsies in monkeys and their relation to human pathology. Brain 1984;107:619-36.

12 Buttner-Ennever JA, Henn V. An autoradiographic study of the pathways from the pontine reticular formation the pathways from the pontine reticular formation
involved in horozontal eye movements. Brain Res 1976; involved in

13 Cohen B, Henn V. Unit activity in the pontine reticular formation associated with eye movements. Brain Res 1972;46:403-10.

14 Highstein SM, Maekawa K, Steinacker A, Cohen B. Synaptic input from the pontine reticular nuclei to abducens motoneurons and internuclear neurons in the cat. Brain Res 1976;112:162-7.

15 Miller Fisher C. Some neuro-opthalmological observations. J Neurol Neurosurg Psychiatry 1967;30:383-9.

6 Buttner-Ennever JA, Cohen B, Pause M, Fries W. Raphe Nucleus of the Pons containing Omnipause Neurons of the oculomotor system in the monkey, and its homologue in man. J Comparative Neurology 1988;267:307-21.

17 Strassman A, Evinger C, McCrea RA, Baker RG, Highstein SM. Anatomy and physiology of intracellularly labelled omnipause neurons in the omnipause neurons in the cat
Brain Res 1987;67:436-40.

18 Keller EL. Participation of medial pontine reticular forma- 
tion in eye movement generation in monkey. $J$ Neurotion in eye movement

19 Zee DS, Robinson DA. A hypothetical explanation of saccadic oscillations. Ann Neurol 1979;5:405-14.

20 Scudder CA. A new local feedback model of the saccadic burst generator. J Neurophysiol 1988;59:1455-7

21 Kaneko CRS, Fuchs AF. The effect of ibotenic acid lesions of the omnipause neurons on saccadic eye movements in the monkey. Neuroscience Abstracts 1987;13:392.

22 Ridley A, Kennard C, Scholtz CL, Buttner-Ennever JA Summers B, Turnbull A. Omnipause neurons in two cases of opsoclonus associated with oat cell carcinoma of the lung. Brain 1987;110:1699-709.

23 Hanson MR, Hamid MA, Tomsak RL, Chou SS, Leigh RJ. Selective saccadic palsy caused by pontine lesions: Clinical, Psychological and Pathological correlations. Ann Neurology 1986;20:209-17.

24 Buttner-Ennever JA, Mehraein P, Uemura T, Tateishi J, Kanaseki T, Arai Y. A neuroanatomical analysis of the Kanaseki T, Arai Y. A neuroanatomical analysis of the
oculomotor deficits seen in a case of Gaucher disease. Proc oculomotor deficits seen in

25 Strassman A, Highstein SM, McCrea RA. Anatomy and
Physiology of Saccadic Burst Neurons in the Alert Squirrel Monkey. I. Excitatory Burst Neurons. Journal Comp Neurol 1986;249:337-57.

26 Atlas SW, Grossman RI, Savino PJ, et al.. Internuclear Ophthalmoplegia: MR-Anatomic Correlation. American Ophthalmoplegia: MR-Anatomic Corre

27 Loeffler JD, Hoyt WF, Slatt B. Motor excitation and inhibition in internuclear palsy. Arch Neurol 1966;15: 664-71.

28 Pola J, Robinson DA. An explanation of eye movements seen in internuclear ophthalmoplegia. Arch Neurol 1976;33 447-52.

29 Pola J, Robinson DA. Oculomotor signals in medial longitudinal fasciculus of the monkey. $J$ Neurophysiol 1978 ; 41:245-59.

30 King WM, Lisberger SG, Fuchs AF. Responses of fibers in medial longitudinal fasciculus (MLF) of alert monkeys during horizontal and vertical conjugate eye movements evoked by vestibular or visual stimuli. J Neurophysiol 1976;39:1135-49.

31 Cogan DG. Internuclear ophthalmoplegia, typical and atypical. Arch of Opthalmol 1970;84:583-9. 